\title{
A forma eletrônica do hipertexto
}

\author{
Silvana Drumond Monteiro \\ Professora Assistente do Departamento de Ciências da Informação \\ da Universidade Estadual de Londrina. Mestre em Biblioteconomia \\ pela Puccamp. Doutoranda em Comunicação e Semiótica pela \\ PUCSP \\ E-mail:drumond@sercomtel.com.br
}

\section{Resumo \\ Estudo da forma eletrônica do hipertexto. Considerando que a forma - o espaço, semântico e material - produz sentidos, os conceitos de texto, paratexto e hipertexto são estudados para discutir a forma hipertextual, bem como os elementos paratextuais à descrição de sites. \\ A estrutura textual do hipertexto revelou-se uma estrutura menos formalizada que o texto impresso, entretanto com uma lógica/semântica própria que o espaço digital oferece por meio da linguagem html. \\ A descrição, em nível de referência desses documentos, merece uma sistematização oficial, frente às várias propostas que se apresentam na literatura e na Internet, sem deixar de discutir os aspectos científicos envolvidos nesse tipo de atualização.}

\section{Palavras-chave}

Formas textuais; Texto; Paratexto; Hipertexto; Representação da informação; Representação do conhecimento; Descrição.

\section{The eletronic form of hypertext: the knowledge representation versus the information representation}

\begin{abstract}
Eletronic form study of hypertext. Considering that the form the semantics and material spaces - produces senses, the concepts of text, paratext and hypertext are studied to discuss the hypertextual form, as well the paratextuals elements at this description of sites. The textual structure of hypertext developed itself a less formalized structure than the printed text, meanwhile with a proper logic/semantic that the digital space offers through html language. The description, at reference level of these documents, deserves an official sistematization, front to the several offers that are presented in the literature and at Internet. It's important to emphasize the need of discussing the scientific aspects involved in this kind of updating.
\end{abstract}

\section{Keywords}

Text form; Text; Paratext; Hypertext; Information representation; Knowledge representation; Description.

Artigo aceito para publicação em 19/11/99

\section{INTRODUÇÃO}

Com o advento do códex (a forma do livro impresso, qual como conhecemos hoje) no século IV, foi-se estabelecendo toda uma percepção acerca do escrito e consolidada como a "cultura do impresso". Entretanto, com as formas eletrônicas, irá surgir a "cultura do eletrônico" que implica novos paradigmas, seja nas ciências cognitivas, nas quais as tecnologias da inteligência "contribuem para estruturar os espaços cognitivos dos indivíduos e organizações" (Lévy, 1996, p. 53), seja na leitura, onde "as formas se modelam graças às expectativas e competências atribuídas ao público por elas visado, mas, sobretudo, porque as obras e objetos produzem o seu nicho social de recepção..." (Chartier, 1994, p.21), seja na educação, implicando ainda, mudanças ou influências da estrutura cognitiva relacionadas à aprendizagem, o que ocorre de maneira muito visível na ciência da informação.

Nessa última área, os conceitos já consolidados na cultura do impresso precisam ser repensados para contemplar ou reformular as representações da informação em função da relação direta da nossa área com as formas textuais. A partir dessa ordem bibliográfica, construída na sociedade, fez-se possível a descrição bibliográfica, que é uma convenção bibliotecária visando a identificar os documentos e é objeto de estudo da representação descritiva (catalogação) e da normalização documentária (especificamente a referência bibliográfica). Dentro da descrição bibliográfica, há uma parte chamada descrição física, em que se reflete a materialidade do documento, como número de volumes, páginas, fascículos, colunas, cadernos etc.

Assim sendo, urge a necessidade de abstrair todos os modelos, sejam das fichas, sejam das sínteses, sejam dos espaços semânticos, e para isto será muito apropriado buscar, na comunicação, na semiótica e na lingüística semântica e textual, toda a teoria dos textos, das linguagens, para então apreendermos esta nova realidade virtual.

Resgatar tal teoria já não era sem tempo, pois a biblioteconomia sempre usou o termo "informação" à sua área de abrangência, talvez com muita propriedade, pois, ao contrário da análise do discurso, o processo da área é, de fato, a análise documentária, que visa a transformar o 
conhecimento representado nos livros, periódicos etc. em representação da informação, elaborando bancos de dados e transformando todo o conhecimento em memória da ciência (e da humanidade), dando assim à ciência, em especial, e ao conhecimento, em geral, o status de referência. Então, em última análise, a informação é referência do conhecimento, ou seja, mantém uma conexão dinâmica com o conhecimento.

Conforme se pode deduzir, o conhecimento codificado em informação repassa o conhecimento ao usuário, para que este possa recuperá-lo. Pronto! Fez-se a transferência da informação.

Se de maneira muito rápida descreveu-se todo o processo da biblioteconomia, ao observar novamente o modelo, nota-se que em nenhum momento falou-se em comunicação. Não há comunicação na área, há transferência da informação; não há conhecimentos com suas macroestruturas textuais e superestruturas, há modelos e representações.

Então, se o conhecimento é o objeto de trabalho da biblioteconomia/ciência da informação, tendo como objetivo transformá-lo em informação, e a análise documentária é o processo (que possui como sustentação as representações descritiva e temática), seria bom não esquecer que objetivo e processo são momentos posteriores do conhecimento representado e da comunicação, e por fim das formas textuais. Por isso, a atualização da área da ciência da informação não pode prescindir de tais teorias e abstrações (representação do conhecimento).

Ainda no contexto das representações, a normalização deve ser apreendida com a abstração devida, ou seja, não existe normalização ou formalização sem a produção de textos, e estes são a representação do conhecimento. Cada forma textual reflete uma ação ou pensamento (intenção) e visa a atingir um leitor específico, possuindo canais também específicos de comunicação (ou de transferência de informação) e, portanto, um nível apropriado de normalização, objetivando atender às exigências anteriormente mencionadas. Compreender o paradigma, de fato, da informação registrada, é condição a priori para filosofar sobre a mudança de paradigma da informação.

Nesse sentido, pensando em descrever as formas eletrônicas das web-pages, como são as disponíveis na rede Internet, é que se propôs a desenvolver esse tema, pois acredita-se que esses dados são indispensáveis à atualização do conteúdo programático de algumas disciplinas da biblioteconomia. Pensando ainda na "descrição física" ou digital dessas formas imateriais, vê-se a importância de estudá-las com objetivo de fornecer elementos de discussão às representações da informação.

\section{FORMA}

A forma ou apresentação formal é o conjunto de elementos e dispositivos que compõem os documentos e é resultado de determinada forma textual ou, antes de tudo, de determinada linguagem.

Conforme resgatados na pesquisa de Monteiro (1996), todos estes dispositivos foram desenvolvidos à apresentação do objeto livro na sua longa evolução histórica. São eles: sobrecapa, orelha, capa, lombada, marcador, indicador, falsa folha de rosto, errata, folha de rosto, dedicatória, epígrafe, agradecimentos, prefácio, lista de ilustrações, lista de abreviaturas, sumário, resumo, introdução, desenvolvimento, conclusão, notas, anexos, glossário, referências bibliográficas, bibliografia, índice, suplemento, colofão, encarte, título corrente, paginação, citações e numeração progressiva dos capítulos. Vale ressaltar que a percepção da forma ultrapassa a estética, ou seja, ela compreende a forma da unidade discursiva constante nos documentos.

Monteiro (1996), pesquisando a forma do livro impresso, retoma a história deste objeto gráfico para demonstrar que o texto não existe em si mesmo, isolado de toda a materialidade.

É por intermédio desta materialidade da forma impressa que a unidade discursiva vai se ordenando de maneira a tornar inteligível o texto. Foi assim que surgiu a fragmentação do texto em capítulos, frases, brancos marginais, alíneas etc., fornecendo uma leitura mais espaçada.

Para Chartier (1994, p.105), foi o códex, na sua acepção tipográfica, que modificou " em profundidade os usos, as circulações, as compreensões de um 'mesmo' texto”, referindo-se aos recortes bíblicos e seus verbetes, às gravuras, à folha de rosto, à paginação etc.

McKenzie (1986) demonstra a relação da forma com a recepção da leitura quando as peças de William Congreve (final do séc. XVII para o séc. XVIII) sofrem mudanças formais aparentemente sutis, como a numeração das cenas, indicação nas margens de nome de quem fala, e a menção de entradas e saídas. Ou seja, estas mudanças fornecem uma nova leitura com grau maior de inteligibilidade (em função da melhor legibilidade da forma impressa). 
Nesse sentido, Chartier (1991, p. 178) afirma que os leitores não se confrontam nunca com textos abstratos ideais, separados de toda materialidade, mas,

"Manejam objetos cujas organizações comandam sua leitura, sua apreensão partindo do texto lido. Contra uma definição puramente semântica do texto, é preciso considerar que as formas produzem sentido, e que um texto estável na sua literalidade investe-se de uma significação e de um estatuto inéditos quando mudam os dispositivos do objeto gráfico que o propõem à leitura."

Assim sendo, a forma (estrutura semântica e material), enquanto conceito, transcende tanto o estruturalismo, definição semântica do texto, como a normalização, enquanto visão eminentemente material dos textos.

A organização formal do livro, que reflete toda esta materialidade, precede o livro impresso, isto é, começou nos livros manuscritos, na Alexandria (290 a.C.). Os alexandrinos criaram uma criteriosa normalização para as suas edições, que, além de apresentar sumário, índice, glossário e tabelas explicativas, também catalogavam, revisavam e comentavam as obras (Araújo, 1995).

Já nos livros impressos, a normalização do texto surgiu de uma preocupação filológica: a preocupação dos editores em reproduzir traduções e edições fidedignas levou a uma normalização do "texto que davam como definitivo para publicação, o que significava recuperá-lo no particular e padronizá-lo no conjunto." (Araújo, 1995, p. 55)

Toda essa normalização do texto consolidou-se com o discurso científico, no qual devem-se seguir os cânones exigidos pela comunidade científica.

Nessa medida, percebe-se que a acepção de nota enquanto nota bibliográfica, isto é, ligada à documentação, surgiu a partir do momento em que também surgiu a necessidade de documentar trabalhos, que foi possivelmente no início do século XIX, na universidade alemã, e dos resultados avançados nela realizados que resultaram no saber moderno e no reconhecimento da necessidade de indicar cuidadosamente as fontes de informação (Hodgson apud Amorim, 1981).

Monteiro (1996) comprova que o conceito de notas, hoje, está ligado à acepção de notas bibliográficas. Embora as notas já existissem nos manuscritos, embora já existissem citações, esta relação não havia sido estabelecida, tendo as notas o caráter explicativo e elucidativo ao texto.
Percebe-se como as exigências do saber e da leitura vão construindo a unidade discursiva (leia-se forma) para atender a uma inteligibilidade.

Por outro lado, cada forma discursiva guarda as suas especificidades. Cerca de 50\% dos autores dos best-sellers dos livros comerciais de não-ficção que citaram (de acordo com a pesquisa de Monteiro, 1996), ainda o fazem sem a preocupação de indicar a fonte, repetindo o comportamento, por exemplo, de Tomás de Aquino em Suma Teológica (1215), que cita Aristóteles referindo-se tão somente "ao filósofo."

Partindo desse pressuposto, não existe texto ou autor sem a forma, seja ela qual for, pois segundo Chartier (1994, p.17),

"Deve-se lembrar que não há texto fora do suporte que o dá a ler (ou a ouvir), e sublinhar o fato de que não existe a compreensão de um texto, qualquer que ele seja, que não dependa das formas através das quais ele atinge o seu leitor."

Lévy (1996) aponta como "tecnologias da inteligência" as tecnologias da informação, uma vez que a forma atinge o seu leitor, organizando o espaço das funções cognitivas. Considera-se também a forma impressa como tecnologia da inteligência, por construir e representar a episteme ocidental na qual foi formulada uma ordem bibliográfica, sobre a qual a biblioteconomia estabilizou-se.

A ordem dos livros, consolidada na cultura do impresso, por meio da sua forma, que implica a ordem das lombadas, das bibliotecas e da leitura, está passando por uma mudança radical com as novas tecnologias do terceiro milênio.

Na vida digital, livros, periódicos, palestras e conferências tornam-se escritos na linguagem de hipertexto. Acabase a relação de documento com a forma no sentido da materialidade.

Assim como na história, primeiro o fato se dá empiricamente e depois a teoria o apreende e explica-o. Primeiro deu-se a forma e posteriormente a padronização bibliotecária. Ou seja, a biblioteconomia apreendeu a cultura do impresso e a padronizou.

Tal padronização, designada "ordem bibliográfica", foi estabelecida a partir dos conceitos que o códex tornou possível, tais como paginação, sumário, citações, referências, resumo, autor, título, dentre outros que vieram a fazer parte das representações bibliográficas, como o conceito de representação temática e descritiva. 
Como se pode deduzir, não há, e não pode haver, a separação dicotômica entre "forma e conteúdo", e sim uma relação dialética ou ainda única, sendo que não existe forma sem conteúdo ou conteúdo sem forma, e nessa estreita relação fenomenológica entre o meio e a linguagem existem as múltiplas facetas de como a forma atinge seu leitor e produz sentidos.

Por isso, ao estudar as formas eletrônicas, acredita-se que novas linguagens consolidarão novas formas textuais, pois conclui-se que "novos leitores criam textos novos, cujas significações dependem diretamente de suas novas formas." (Chartier, 1994, p. 20)

O livro eletrônico ainda se encontra mais apropriado para informações factuais e referenciais como enciclopédias e bibliografias. Entretanto, vêem-se proliferar nas redes os documentos eletrônicos e o hipertexto e hipermídia, ou seja, os textos completos, full texts.

Lancaster (1995, p. 518-9) traça a evolução das publicações eletrônicas desde seu aparecimento, conforme demonstrado a seguir: (tradução nossa)

a) o uso do computador para gerar publicação (convencional) impressa na década de 60;

b) a distribuição do texto na forma eletrônica quando a versão eletrônica é_a exata equivalência da versão impressa e pode gerar a versão impressa;

c) distribuição somente na forma eletrônica;

d) a geração de novas publicações que exploram a verdadeira capacidade eletrônica.

A fase (a) cita como exemplo a produção do Index Medicus, pela National Library of Medicine, na qual o computador foi utilizado para gerar a forma impressa. Esta fase coexiste com nossos dias, em que a editoração eletrônica é utilizada pelos editores para gerar os livros impressos.

A fase (b) aplica-se às publicações secundárias, como os serviços de indexação e resumos, distribuindo a versão eletrônica.

O último estágio ainda não se realizou completamente e aplica-se ao hipertexto e hipermídia, uma vez que ainda existem os livros impressos. Aliás, o momento é o da coexistência: forma impressa e forma eletrônica.

Macedo (1996), discorrendo sobre os catálogos eletrônicos, constatou que a Web continha algo entre 30 a 50 milhões de páginas. Considerando que em média uma página contém em torno de 50 palavras ou 7 kbytes de texto, pode-se dizer que a web possuía (na época) entre 200 e 330 gigabytes de texto, e isto com um crescimento de $20 \%$ ao mês. No Brasil, foram registrados, em agosto de 1998, 3392 milhões de usuários da rede Internet, sendo que 3 mil novos usuários aderem à rede todos os dias, demonstrando assim números expressivos do crescimento deste tipo de comunicação, refletindo a coexistência das formas impressas e eletrônicas na sociedade, cabendo identificar a verdadeira função destas últimas.

Sobre as formas eletrônicas, Chartier (1994, p.101) constata que

“...a representação eletrônica dos textos modifica totalmente a sua condição, ela substitui a materialidade do livro pela imaterialidade de textos sem lugar específico; às relações de contigüidade estabelecidas no objeto impresso ela opõe a livre composição de fragmentos indefinidamente manipuláveis; à captura imediata da totalidade da obra, tornada visivel pelo objeto que a contém, ela faz suceder a navegação de longo curso entre arquipélagos textuais sem margens nem limites."

Isto significa que a mudança das formas e dos dispositivos por meio dos quais um texto é exposto pode criar novos públicos e novos usos para ele.

Os textos eletrônicos, se destituídos de materialidade, são, no entanto, instituídos de uma forma que poderá alterar o conceito de acervo, de bibliotecas, dos livros e sobretudo das relações da leitura. Qual é esta forma?

No ciberespaço os documentos são oriundos de fontes eletrônicas, disponíveis nos formatos FTP (File Transfer Protocol) sites, gopher sites, HTTP (word wide web) sites, telnet sites, e-mail discussion lists.

O hipertexto (HTML - Hypertext Markup Language ) tratase não só de um artifício gráfico, mas de uma maneira diferente de leitura alterando o modo de os usuários raciocinarem. $\mathrm{O}$ hipertexto permite a interatividade, a navegação contígua sem limites de espaço físico e de margens. É uma linguagem padrão para os documentos em sistemas Web (WWW) que usam o HTTP (Hypertext Transfer Protocol).

O formato Gopher apresenta a informação em uma estrutura hierárquica de menu, portanto mais apropriada para computadores sem os recursos da multimídia.

O formato FTP (File Transfer Protocol) é utilizado para transferência de arquivo. 
A multimídia reúne imagens, vídeos, sons, dados e texto em um mesmo programa, possibilitando ao usuário variada gama de interatividade dantes jamais conseguida no material impresso.

Entender os dispositivos por meio dos quais esses textos são expostos, especialmente as web-pages de sites (incluindo a home-page), foi o ponto inicial de motivação para estudar o hipertexto.

\section{O HIPERTEXTO, O TEXTO E O PARATEXTO}

Pretende-se abordar a forma no contexto das formas eletrônicas em dois aspectos estruturais: o texto e o paratexto, principalmente o deslocamento ou aproximação deste último para o hipertexto.

O hipertexto é entendido como uma forma eminentemente eletrônica, e para tanto foram analisados aqueles que só podem estar disponíveis em formato eletrônico, não possuindo o equivalente impresso, especialmente no item sobre a apresentação textual. Sua característica principal é a apresentação da informação de uma maneira não-linear, como se a organização seqüencial e linear do papel fosse desmantelada.

Para compreender o hipertexto, tem-se de estabelecer uma relação com a unidade textual do material impresso, na qual Le Coadic compara (1996, p. 59),

"Em que um documento hipertexto difere de um documento convencional de papel? Num documento de papel, seja um artigo ou romance, as estruturas físicas e lógicas estão muito próximas. Fisicamente, o documento é uma longa seqüencia linear de palavras que, por razões de ordem prática, foi dividida em linhas e páginas. A estrutura lógica do documento também é linear: combinam-se as palavras para formar frases, as frases, parágrafos, os parágrafos, capítulos, etc. Se o documento apresentar uma estrutura lógica hierarquizada, como acontece com muitos documentos científicos, esta hierarquia será reproduzida de forma linear: resumo, introdução, primeiro parágrafo, segunda parte, e assim por diante até conclusão."

Entretanto, segundo o autor, algumas obras, pelo seu arranjo mais sofisticado, fazem lembrar o uso de um hipertexto, como, por exemplo, as enciclopédias, os dicionários e algumas obras de referência, em função do caráter remetente das mesmas, onde a estrutura lógica encontra-se armazenada em várias estruturas físicas impressas, resultando em uma consulta um pouco mais complexa.
O que diferencia o conceito de hipertexto dos documentos impressos é que, no hipertexto, "a informação encontrase de fato, armazenada em uma rede de nós conectados por ligações", podendo ser nós que contêm gráficos, textos, sons e imagens, os chamados documentos hipermídia. "As ligações unem essas entradas entre si: do texto lido aos textos a ler, da ilustração ao trecho de música... É sempre possível modificá-los ao contrário do documento impresso." (Le Coadic, 1996, p. 60)

Quer dizer, a maneira de buscar as informações no hipertexto pode até ser aparentemente comparável ao manuseio de uma obra de referência, como uma enciclopédia, por exemplo. Entretanto, a interatividade na forma eletrônica do hipertexto é maior e com mais recursos, uma vez que a informação não se esgota em uma ou algumas unidades físicas, sem contar que o bit usa menos espaço em seu suporte ou meio de registro que a palavra impressa.

Pode-se consultar em um só cd-rom uma enciclopédia que contém 26 volumes e interagi-los a partir da busca de informação. Ou seja, as estruturas lógica e física são intercambiáveis, pois o espaço físico eletrônico permite esta associação, ao passo que, para fazer os cruzamentos que um assunto necessita em uma enciclopédia impressa, tem-se de manusear várias estruturas físicas, além de o texto apresentar-se em seqüência linear. A forma eletrônica abriga a informação na razão inversa da forma impressa, onde várias estruturas lógicas situam-se em uma estrutura física (digital).

Essa é a diferença do hipertexto para os outros documentos impressos e outros eletrônicos, pois a forma de armazenamento da informação possui uma

"Estrutura associativa que reproduz, muito de perto, a estrutura da memória humana e pode tornar-se seu complemento intimo e ampliado. Permite substituir as estruturas clássicas arborescentes da informação por estruturas mais ricas e mais complexas, organizadas em redes, mostrando um mero infinito de caminhos, abertos a todas as navegações e interligando múltiplos objetos." (Le Coadic, 1996, p. 61)

Na verdade, outras relações de sistemas de remissivas que permitem uma interatividade de informações podem ser estabelecidas. Por exemplo, um índice (catálogo) de biblioteca, um current contents, um índice de um livro, o intercambiamento da citação com a referência bibliográfica são todos exemplos de interatividade. 
São sistemas ou arranjos desenvolvidos para organizar acervos ou documentos, com que o bibliotecário possui muita familiaridade, entretanto todas estas relações ficam restritas à materialidade (estrutura física) do documento ou acervo e à quantidade de conteúdo (estrutura lógica) que esta pode conter.

Lévy (1996, p. 34) também relaciona o hipertexto com os documentos impressos:

"Estamos hoje tão habituados com essa interface que nem notamos mais que existe. Mas no momento em que foi inventada, possibilitou uma relação com o texto e com a escrita totalmente diferente da que fora estabelecida com o manuscrito." (Lévy, 1996, p. 34).

Os elementos do paratexto (título, citações, referências) e outros, como paginação, sumário e índice, são elementos de normalização que foram desenvolvidos à forma impressa, e são designados interfaces da escrita. Entretanto, Lévy (1996) admite que o hipertexto tem traços de várias outras mídias, mas constitui-se em uma rede original de interfaces. $\mathrm{O}$ que diferencia o texto do hipertexto é a velocidade, "a quase instantaneidade da passagem de um nó a outro permite generalizar e utilizar em toda sua extensão o princípio da não-linearidade." Lévy (1996, p. 37)

A página, que é a unidade de dobra do texto impresso, torna a leitura do códex uniforme e linear. $\mathrm{O}$ hipertexto possui todas as dobras possíveis, pois o mesmo, por meio de um novo meio de comunicação, o digital, e de um novo elemento na comunicação, o sinal, tem potencialidades dantes jamais imaginadas.

Várias são as abordagens possíveis ao se estudar o texto, podendo ser estudado buscando os elementos de organização geral e assim compreender a sua estrutura esquemática e temática, de acordo com o aporte teórico da lingüística textual (Dijk, 1992).

Nesse contexto, a estrutura esquemática, chamada de superestrutura, compreende o esquema ou partes lógicas que cada discurso guarda em si. São os roteiros subjacentes aos textos que fornecem a sintaxe completa à macroestrutura.

A estrutura temática ou macroestrutura busca o sentido, sendo o resumo um exemplo de macroestrutura semântica do texto.

O texto pode ser estudado ainda, no âmbito da lingüística semântica para estabelecimento de controle de vocabulário utilizado na representação temática. Itens como sintagmas (palavras-chave), análise documentária e descritores fazem parte integrante do texto.

Percebe-se que as teorias desenvolvidas à linguagem verbal para estudo do texto (e não para a significação) não contemplam o estudo do hipertexto.

Assim avançar-se-á o conceito de estrutura textual, uma vez que os roteiros da superestrutura existentes nos discursos descritivos, narrativos e dissertativos estão relacionados à linearidade dos textos impressos e às lexias (sentenças) mais longas e hierárquicas, ou seja, à linguagem verbal. Isso não significa que não exista discursividade nas outras linguagens.

Vale a pena dizer que não interessa estudar a discursividade no hipertexto, ou seja, o plano de exposição dos discursos (descrição, narração e dissertação) e seus esquemas superestruturais. A macroestrutura não será estudada porque também não há o interesse com a significação, neste artigo. Parece indicar uma necessidade de afastamento de um pensamento verbalista, mas, por ora, parece difícil fazê-lo de todo.

Para direcionamento teórico, considerar-se-ão as estruturas mais gerais, em termos de organização do texto, tomado em abstrato sobre o meio, sendo esta a discussão mais propícia para a comparação do texto impresso e o hipertexto, ou seja, da estrutura linear e a interativa.

Toda estrutura textual é também cognitiva, pois organiza o espaço das funções cognitivas mediante esquemas textuais. Assim, a estrutura linear organizou o texto impresso desenvolvendo uma série de elementos para o texto, além do texto, designados "paratexto", por Le Coadic (1996).

Então, estudar o paratexto no hipertexto (ou mesmo nas formas impressas) significa estudar as formas textuais no âmbito mais geral, buscando, dentro destes espaços semânticos, aspectos de lógica e sua interação com a estrutura cognitiva textual.

O paratexto está mais relacionado com os elementos de normalização do texto e, segundo Le Coadic (1996, p. 58):

"orla textual que contorna o texto propriamente dito, o paratexto é um instrumento de adaptação entre um texto e um público. Tem por função essencial motivar a leitura, orientá-la e garantir sua pertinência, bem como balizála. Compreende o título, o(s) nome(s) do(s) autor(es), endereço, resumo, palavras-chave, citações ou referências, etc." 
Relacionando o texto e o paratexto com a representação do conhecimento e posteriormente com a representação da informação, os métodos de análise na biblioteconomia baseiam-se nos documentos e no conhecimento. Segundo Le Coadic (1996), são métodos de análise quantitativa e qualitativa de textos, sendo uns apoiados no paratexto e outros no texto.

De acordo com a figura 1, a representação descritiva e a referência bibliográfica, respeitando o nível de cada uma delas, baseiam-se na origem do documento, ou seja, na escolha das entradas que o descrevem: autores, editores, lugar, data, língua de publicação, título do documento, forma de apresentação etc. Para tanto, utilizam-se mais os elementos paratextuais.

A representação temática utiliza-se de métodos com base lingüística na indexação, classificação e elaboração de resumos. Nesse sentido, trabalha-se mais com a análise do texto, entretanto elementos do paratexto como o resumo e palavras-chave, além da referência, são utilizados na indexação.

Como se pode ver, o texto, a partir do processo de normalização*, gera elementos que por sua vez são utilizados na representação temática e na representação descritiva e na referência bibliográfica (ambas constituindo descrição bibliográfica).

As citações fazem parte do texto e indicam as relações semânticas do discurso do autor e servem para estudos ou análise de conteúdo e análises cientométricas.

Outros elementos devem ser somados ao conceito de paratexto, pois são elementos de organização textual designados interfaces da escrita por Lévy (1996), tais como sumário, índices, cabeçalhos aparentes, apresentação de imagens (especialização da informação) e dispositivos materiais de suporte (no caso dos documentos impressos) pelos quais um texto possui uma localização físicoespacial, que são, no texto, indicativos da estrutura esquemática.

\footnotetext{
* Deve a normalização ser compreendida como interfaces desenvolvidas para a tecnologia da inteligência, em especial o livro, mas extensivas a todos os textos impressos, uma vez que esses são a representação do conhecimento e, portanto, registros de toda a episteme ocidental. Tais interfaces são partes fundamentais à cognição, pois proporcionam uma legibilidade dos textos e, portanto, maior inteligibilidade na leitura, e são também condições sine qua non ao tratamento da informação, à qualidade do objeto gráfico e ao controle bibliográfico universal.
}

\section{FIGURA 1}

O texto e o paratexto (representação do conhecimento) e a representação da informação

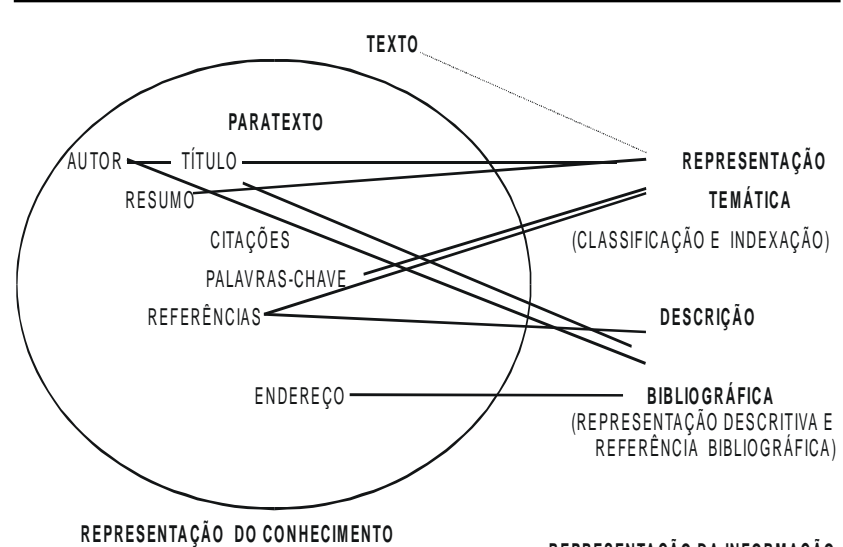

REPRESENTAÇÃO DA INFORMAÇãO

Essa ordem (bibliográfica) significa um estágio de formalização dos documentos impressos, do códex tipográfico ao periódico científico, gerando as fontes secundárias (com alto grau de interfaces e impregnadas de representação da informação).

\section{DISCUSSÃO}

Apesar da discussão em torno das informações eletrônicas, se são comunicação formal ou informal, especialmente as web-pages de sites, é necessário que se busque a compreensão das formas textuais dessas, até mesmo para fornecer elementos às representações da informação, mas o objetivo é buscar os elementos paratextuais (e outros complementares de interface da escrita) visando à referenciação eletrônica, bem como discutir a estrutura textual dessa nova forma textual.

Assim sendo, os elementos de interface da escrita hipertextual de um site foram buscados para tentar analisar uma aproximação (ou não) da formalização impressa com esse tipo de texto, considerado eminentemente eletrônico. Ao mesmo tempo, buscou-se levantar quais são as interfaces específicas sob as quais esse texto apóia sua representação. Inicialmente, observam-se os elementos infracitados, como funcionariam em uma estrutura interativa:

$\Rightarrow$ sumário;
$\Rightarrow$ índices;
$\Rightarrow$ apresentação de imagens etc. 
Posteriormente, analisaram-se algumas web-pages, incluindo a home page do site, para observar se os elementos do paratexto existiam nas mesmas, pois alguns são necessários à construção de uma descrição bibliográfica (em nível de referência), tais como:

$\Rightarrow \quad$ título;

$\Rightarrow$ autores;

$\Rightarrow$ endereço (aqui entendido no hipertexto como endereço eletrônico).*

Entretanto, à descrição bibliográfica são necessários mais elementos de identificação, como:

$\Rightarrow$ paginação (quando impresso);

$\Rightarrow$ dispositivos digitais de localização física da informação (além da paginação);

$\Rightarrow \quad$ títulos de partes (caso seja utilizada uma parte do site).

\section{Elementos de apresentação textual do hipertexto}

A informação hipertextual está disposta em forma de rede, e não estruturada hierárquica e linearmente por meio da dobra de página impressa.

A impressão que se tem é que todos os tipos de documentos estão em um espaço físico, ou seja, da informação às referências deste e vice-versa. É como se entrássemos em uma biblioteca e, a partir de uma estrutura física, tivéssemos todas as estruturas lógicas (conteúdo) remetendo-se o tempo todo. Nessa medida, a separação entre as obras ou mesmo entre as obras e os autores, característica dos documentos impressos, tende a desaparecer, fazendo com que as obras, no espaço digital, façam parte de um "imenso plano semiótico desterritorializado.” (Lévy, 1998, p. 106)

A estrutura lógica (conteúdo) está junto com a estrutura física, no mesmo espaço digital, e não se encerra na consulta de uma informação ou em um número limitado de informações, uma vez que, através da navegação, vários sites estão "linkados" entre si.

Cabe ressaltar que nessa estrutura lógica, em sua maioria, o que há é informação (e não conhecimento). Mas, mesmo assim, é difícil apreender a sua totalidade, porque não há uma macroapreensão, ou seja, a lógica semântica do objeto delimitado por uma forma física. Aos programadores cabe criar esta lógica (quando é desenhada a home page e o site).

\footnotetext{
* Na forma impressa, o endereço pode ser considerado o da editora, ou do autor (em algumas fontes), ou mesmo o nome da editora (que não deixa de ser o endereço da propriedade de edição) ou ainda o endereço do texto no documento, ou seja, a paginação.
}

Para nós, ela é oculta, com exceção de algumas home pages que dão ao leitor o mapa de site, que pode ser comparado ao texto impresso com o sumário. Tal mapa pode aparecer ilustrado, com recursos dos ícones (figura 2), ou na versão text only, conforme a figura 3 .

\section{FIGURA 2}

\section{Home page de abertura do site}

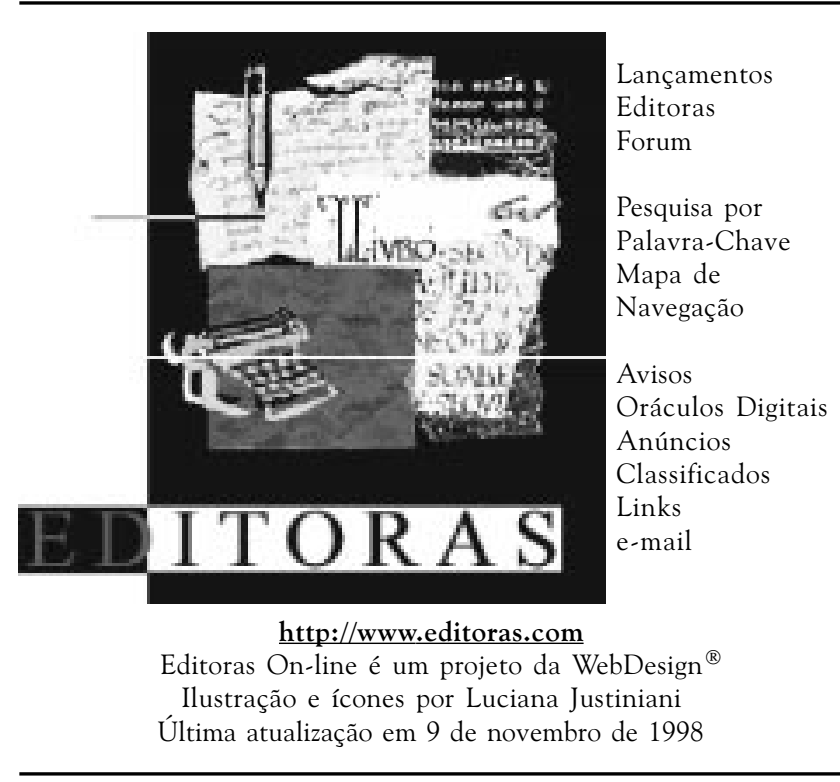

FIGURA 3

Mapa de navegação do site

Editoras Online

http://www.editoras.com

homepage (todo mês, os principais lançamentos do mercado editorial brasileiro)

Fórum (Fórum de Debates sobre literatura)

Lançamentos (Lista dos últimos lançamentos, com capa e comentário) Editoras (editoras que patrocinam este site)

AGIR

Ampersand

Artrium

Bertrand

Campus

Casa Jorge Editorial

Companhia das Letras

Civilização Brasileira

Dominio Público

Ediouro

Geração Editorial

Globo

Gryphus

Jorge Zahar Editor

Luz e vida

Manole
Martins e Fontes

Melhoramentos

Monterey

MultiMais

Nova Fronteira

Objetiva

Pensamento

PNDU

Razão Cultural

Record

Relume-Dumará

Renovar

Revan

Rideel

Rocco

Salamandra

SENAC São Paulo

Temas \& Idéias

UAPÊ

UFMG

UFRJ

Unicamp (veja também o catálogo)

Avisos (anúncios de eventos culturais)

Pesquisa por palavra-chave Oráculos Digitais (aprenda a pesquisar na Internet). 
A estrutura do mapa da figura 3 é aparentemente hierárquica, pois tal representação é aparente, uma vez que as informações estão ligadas ("linkadas") em rede e não há o seccionamento do texto tal qual conhecemos, com a numeração progressiva dos capítulos (sumarização) dos textos impressos. Juntamente com esse sumário, temse o recurso da imagem, ou ícones", assim chamados no espaço cibernético.

Tal mapa, na home page do site aparece representado verticalmente (figura 2), ou seja, palavra debaixo de palavra, e, nas outras web-pages, dentro do site, costuma aparecer horizontalmente (como se fosse o cabeçalho da folha, mas funciona como sumário), é o recurso que leva ao leitor à informação ou item desejado. Este recurso é o HTML (Hypertext Markup Language) que torna o hipertexto um documento eminentemente eletrônico. "Ao ritmo regular da página se sucede o movimento perpétuo do dobramento e desdobramento de um texto caleidoscópio". (Lévy, 1996, p. 41)

A visão de um caleidoscópio é mágica! Novos prefixos como mega e hiper estão sendo emprestados do grego para designar toda esta informação "caleidoscópica". Mas agora pensando na leitura, esta imagem de sucessão rápida e mutável de impressões e de sensações aplicada à informação não forneceria um panorama fragmentado e pouco aprofundado do conhecimento?

Nesse sentido, Lévy (1996) aponta que, para entender e memorizar o conteúdo dos textos (impressos), é necessário que os leitores depreendam sua macroestrutura textual e que o oposto é mais difícil, ou seja, abstrair e integrar o sentido de um texto a partir das fragmentações (hipertexto).

$\mathrm{Na}$ forma impressa, onde a unidade textual é mais aprofundada ou hierárquica, própria dos textos de nãoficção, existe uma ligação que reproduz esta organicidade: a numeração progressiva dos capítulos, que leva a um efeito extremamente mnemônico, exatamente por demonstrar a subordinação dos vários capítulos dentro da unidade maior, que é o texto, ajudando justamente a depreender a macroestrura textual. Talvez esta seja uma maneira de explicar a linearidade da forma impressa que não existe no hipertexto.

\footnotetext{
* Uma atualização possível, a partir da semiótica peirciana, por Santaella (ver em referências), o ícone está ligado à qualidade de sentimento, à primeiridade, características da linguagem sonora e não da visual. $\mathrm{O}$ signo indicial, em função da conexão dinâmica com o seu objeto, quer seja referencial, está ligado à linguagem visual. Não significa que o signo imagético não possua sua face icônica, mas que a proeminência do ícone encontra-se no sonoro, assim como a imagem está na proeminência do índice.
}

FIGURA 4

\section{Mapa de links do site}

\section{EDITORAS}

Livrarias On-line

Livraria Siciliano (Brasil)

Livraria Cultura (Brasil)

Livraria Booknet (Brasil)

Livraria 115 (Portugal)

Livraria Arco Íris (Portugal)

The Internet Book Shop (Inglaterra)

Le site de la France (França)

Luso-Brazilian Books (EUA)

Barnes and Noble (EUA)

Amazon Stacks (EUA)

Jornais On-line

Radiobrás

Banca de revistas

O Globo On

Jornal do Brasil

Jornal Folha de São Paulo

O Estado de São Paulo

Agência Estado (servidor brasileiro)

Agência Estado (servidor americano)

Jornal da Tarde

Jornal O Povo Online (Fortaleza)

Diário do Nordeste (Fortaleza)

Top of the news

Revistas On-line

Intervista- Revista da Internet

Doce de Letra. Revista sobre literatura infanto-juvenil

Revista de Sociologia e Política

Book-wire- The First Place to Look for Book Information

Alice.it

Wired

Wired 5.03- Entrevista com Umberto Eco

Internet Word

Online Educator

Literatura

Cordel na Internet

Carlos Drumond de Andrade

Fernando Pessoa

Literatura Interativa da Aplub

Labyrinth Home-Page

On-line books: The Virtual Library

\section{Bibliotecas}

Biblioteca Virtual de Estudos Culturais (CNPq) Arquivo Nacional do Brasil- Outros arquivos Biblioteca Nacional de Lisboa

(obs: o mapa de links continua, no original)

$$
\text { Homepage Editoras Lançamentos Escreva-nos! }
$$


Assim sendo, alguns sites estão indicando o mapa de links, conforme a figura 4 , fornecendo ao leitor uma sensação de apreensão da organização textual.

Os outros elementos paratextuais, tais como o resumo, citações e referências existentes em um texto, não são necessários à referenciação e percebe-se que não estão presentes nas web-pages, pois tais elementos fazem parte de discursos que possuem alto grau de formalização do conhecimento, tais como artigos, teses, projetos, entre outros documentos científicos.

Questionar, neste momento, o livro eletrônico, parece significar que as grandes formas textuais não são transportadas facilmente para o meio digital, e este último criará novas formas textuais específicas, como o hipertexto das web-pages, por exemplo.

Para essa discussão, há de se considerar a linguagem formal (dos livros impressos) versus a linguagem imagética (da multimídia), pois esta última atende perfeitamente ao lúdico, sendo apropriada aos livros infantis e às informações ricas em interfaces, no caso livros referenciais como as enciclopédias, e das bases de dados. As novas formas textuais são criadas quando novos espaços cognitivos são aperfeiçoados, e uma forma carregada de formalidade textual semântica, como o livro de literatura, por exemplo, não será transportado facilmente para uma forma hipertextual.

Chartier (1994, p. 106) afirma que o livro de Dante, Shakespeare e Galileu não é qualquer livro, mas,

"A metáfora do livro do mundo, do livro da natureza, tão potente, na Idade Moderna, encontra-se fixada às representações imediatas e enraizadas que associam naturalmente a escrita ao códex. O universo de textos eletrônicos significará, necessariamente, um distanciamento em relação às representações mentais e às operações intelectuais especificamente ligadas às formas que teve o livro no Ocidente há dezessete ou dezoito séculos." (grifo do autor)

Documento e informação possuem uma relação intrínseca indissociável consubstanciada na linguagem, criando uma forma textual que é o todo, sem a dicotomia forma (para documento) e conteúdo (para a informação), em que tais formas textuais produzem sentidos no leitor e formulam conceitos às áreas que trabalham com a informação.

Os índices eletrônicos são chamados, na Internet, de oráculos digitais. Cada mecanismo de busca existente pode ser comparado aos antigos oráculos, divindades que respondiam às consultas e orientavam os crentes na Grécia e Egito, e os hebreus, fenícios e babilônios, de acordo com Charlab (1998).

Os oráculos, enquanto índices, são fontes secundárias e estão no mesmo espaço das fontes primárias que se sucedem, uma a uma, com um simples apertar do mouse.

Alguns sites possuem, também juntamente com a informação (primária) índices que buscam nela mesma algumas informações bibliográficas, no caso de sites de bibliotecas e editoras.

Os oráculos buscam assuntos e outros buscam referências bibliográficas, mas tanto um quanto o outro são uma forma de controle da informação virtual, pois, sem este controle espontâneo, seria impossível encontrar o que se busca na rede. São assim, espaços semânticos sendo organizados para melhor apreensão cognitiva dos usuários.

Por fim, contra a estabilidade que o texto impresso conserva, onde as montagens e desmontagens do sentido serão feitas pelo leitor, o hipertexto automatiza e autoriza todas as (des)montagens possíveis e amplia várias construções do sentido (Lévy, 1998).

\section{ELEMENTOS PARATEXTUAIS DO HIPERTEXTO VISANDO A UMA DESCRIÇÃO (ELETRÔNICA)}

Neste momento, buscaremos discutir os elementos do paratexto arrolados neste artigo, acrescidos de outros elementos necessários à identificação de determinada informação para a elaboração da referência bibliográfica.

A descrição bibliográfica é uma convenção bibliotecária com o objetivo de identificar os documentos, e é objeto de estudo da normalização documentária (referência bibliográfica) e da representação descritiva (catalogação). A primeira objetiva referenciar uma obra citada. Para tanto, utiliza-se não só, mas também dos elementos do paratexto. Essa parte está envolvida com o uso de documentos e informações no processo da construção do conhecimento. Ou seja, ler, pesquisar, escrever, citar e publicar. Faz parte da pesquisa e da elaboração dos originais (documentos) e, mais ainda, da normalização dos textos (forma).

A segunda é uma forma mais complexa de identificar os documentos e é utilizada em bibliotecas ou centrais de catalogação para indicar quais as obras ali existentes. Implica também a organização desses documentos em algum acervo. Não implica a elaboração de originais 
(primários), mas o seu controle e a elaboração de documentos secundários.

Tanto uma quanto a outra, levam em consideração, para a descrição, a forma do documento. Dentro da descrição bibliográfica, existe uma parte chamada descrição física, que é a parte que reflete a materialidade do documento, como volumes, páginas, fascículos, colunas, cadernos etc. Descrever um documento bibliográfico é uma tarefa íntima dos bibliotecários e ocupa lugar de destaque em sua grade curricular. Significa, de uma forma normalizada, descrever um documento, identificando-o em todos os seus aspectos. Trata-se de uma representação simbólica, portanto convencional.

No ano de 1996, começam a ser editados os primeiros documentos sobre referência bibliográfica de documentos eletrônicos.

Em termos de panorama internacional (tirando as listas de discussões sobre o assunto disponíveis na rede), a ISO (International Organization for Standartization) ainda não publicou nada a respeito, mas anuncia uma nova edição da ISO-690, tratando especificamente desta questão.

A APA (American Psychological Association), que publica normas para redação científica na área de psicologia, já tem publicado algumas regras para documentos eletrônicos.

No Brasil, foram publicados alguns documentos sobre o assunto, de autoria de Ferreira \& Kroeff (1996), Martins et al. (1996) e Kraemer et al. (1996).

São documentos nos quais os autores estão preocupados com a apreensão do empírico, pois, de acordo com Ferreira \& Kroeff (1996, p. 4), "aumentou a necessidade dos usuários em saber como referenciar esse tipo de documento que possui características peculiares, tais como:"

a) alguns aceitam alterações, tanto de forma quanto de conteúdo, enquanto outros são imutáveis;

b) podem ser unicamente disponíveis em formato eletrônico, não possuindo equivalente impresso ou em outro suporte qualquer;

c) possuem forma e estilo semelhantes ao documento impresso (exemplo: monografia, seriados, artigos etc.), porém nem sempre as características físicas da publicação impressa estão presentes no formato eletrônico (por exemplo: número de volume, fascículos e páginas).
O hipertexto situa-se no âmbito da alínea b), ou seja, é um documento eminentemente eletrônico, especialmente as web-pages. Portanto as discussões aqui colocadas contemplam essa forma, e somente no momento da referenciação eletrônica, em que os textos possuem o equivalente impresso (como o periódico ou monografia eletrônicos, conforme a alínea c) serão mencionados alguns comentários. Assim sendo, buscou-se levantar os elementos necessários à referência bibliográfica (melhor dizendo, eletrônica) e discutir os mesmos no hipertexto de web-pages diante do que se vem apresentando na literatura.

Retornando aos elementos do paratexto já citados, como o título, autor e endereço (apenas esses - do paratexto necessários à referenciação) parecem ser suficientes à descrição dos documentos eletrônicos (ao contrário das formas impressas), uma vez que a imaterialidade descarta itens como a paginação e/ou dispositivos de localização física da informação. Entretanto, outros elementos ou informações vão se constituindo como parte integrante da referência de documentos eletrônicos, conforme os modelos apresentados.

Para Moura (1996, p. 4), os elementos necessários à referenciação do documento eletrônico são:

$\Rightarrow$ identificação da autoria;

$\Rightarrow$ título da obra;

$\Rightarrow$ local onde o documento encontra-se armazenado;

$\Rightarrow$ data.

Para Kraemer et al. (1996), além dos elementos já consolidados na referenciação dos documentos convencionais, é no elemento notas o espaço adequado das referências, para mencionar as informações que não foram inseridas nos elementos anteriores, tais como:

$\Rightarrow$ vias de acesso ao documento;

$\Rightarrow$ endereço eletrônico;

$\Rightarrow$ disponibilidade do documento.

Assim, essa lógica segue a mesma da ABNT para referência bibliográfica com relação aos documentos impressos e multimeios, tornando fácil, inclusive, a assimilação desse assunto em face da analogia possível com o conhecido e já apreendido. 
As vias de acesso ao documento, segundo Kraemer et al. (1996), dizem respeito à identificação de informações que são obtidas em outros suportes digitais ou fontes disponíveis na rede Internet, ou na WWW.

Mais comumente, utiliza-se, para a referenciação de webpages, o item "disponibilidade do documento", que no caso das autoras seria "Disponível na Internet". (Kraemer et al., 1996).

O endereço eletrônico, em Kraemer et al. (1996) é o "pathway, ou seja, o caminho do site ou da web-page específica. Já no texto de Ferreira \& Kroeff (1996), o endereço eletrônico é denominado de acesso ao site ou a uma parte desse.

Analisando o texto de Ferreira \& Kroeff (1996), percebese que o mesmo traz modelos de referência de documentos eletrônicos segundo a ISO (International Organization for Standardization) a APA (American Psychololical Assaociation) e a MLA (Modern Language Association).

Apesar de contemplar apenas os documentos completos ou de conteúdo, ou seja, monografias e artigos eletrônicos, cabe ressaltar que o modelo da ISO foi transportado (neste artigo) à referenciação de sites e web-pages, que também são capturadas e citadas freqüentemente, e objeto do nosso estudo.

Entretanto, os modelos da ISO têm trazido certo grau de dificuldade, uma vez que novas informações estão sendo acrescentadas, criando assim novos elementos, por exemplo: a inserção da categoria "produtor" (além do habitual autor), "tipo de suporte" após o título (como na representação descritiva), uma série de datas, entre outros.

Dentre os elementos apontados para referenciar full texts, foram transportados aqueles necessários à referenciação do site. Exemplificando:

\section{MODELO 1: ISO apud Ferreira \& Kroeff (1996)*}

MOURA, Gevilacio Aguiar Côelho de. Citações e referências de documentos eletrônicos [on-line]. Recife: jun.1996. Available from World Wide Web:<URL:http://www.elogica.com.br/users/gmoura/ refere.htm $>$ [10 out. 1996]

\section{onde:}

A segunda linha da referência não volta debaixo da terceira letra do sobrenome do autor. [on-line]: identifica o tipo de suporte, sendo que Ferreira \& Kroeff (1996) indicam que a ISO faz a seguinte recomendação:

[on-line] quando localizado na rede Internet;

[disquetes] e [CD-Rom] quando possui o suporte material.

A indicação do suporte entre colchetes, no caso da sugestão da ISO, é a designação "específica" do suporte. A título de comparação, na representação descritiva, após o título, vem a menção da designação genérica, e não específica, do documento.

data:

sendo a primeira, a data de "publicação" juntamente com o local (se houver), por exemplo: Recife : jun.1996.;

a segunda, entre colchetes no final da referência, indica a data de consulta ao site, por exemplo: [10 out. 1996]

No Modelo 1, foram exemplificadas duas datas, mas o excesso de datas, segundo a ISO, mais leva à confusão do que à inteligibilidade da informação na referência. Há também a data de citação e a da última revisão ou atualização do site. Qual delas é a mais relevante? A de citação, a de atualização, de publicação ou consulta? Temse observado, nos autores infracitados, que a menção da data de consulta ou captura da informação eletrônica é a mais utilizada na referenciação.

O local e a data de "publicação" só fazem sentido no caso de monografias que possuem o equivalente em papel, mas não no caso do hipertexto, onde não há publicação impressa, e o lugar não diz muita coisa à referência, pois o acesso se faz por meio do endereço eletrônico, a despeito das distâncias geográficas.

\section{DISPONIBILIDADE DO DOCUMENTO E ACESSO:}

Available from World Wide Web: ou seja, disponível na WWW, e a ISO, de acordo com Ferreira \& Kroeff (1996, p. 8-9) recomenda:

documentos eletrônicos on-line via WWW devem inserir a expressão supracitada seguida da URL (endereço eletrônico) entre o símbolo matemático de par ordenado $<>$, ou seja, "brackets", por exemplo: Available from Word Wide Web: <URL:http://www.elogica.com.br/users/ gmoura/refere.htm $>$ 
$>$ documentos eletrônicos on-line disponíveis nos serviços da Internet, exceto o WWW, devem inserir a expressão "Available from Internet".

Outros autores sugerem a expressão em português, tais como "Disponível na Internet", inclusive para WWW (o que é mais lógico), como no Modelo 2, ou então "Disponível na Internet via WWW", conforme o Modelo 3:

MODELO 2: Kraemer et al. (1996)

MOURA, Gevilacio Aguiar Côelho de. Citações e referências a documentos eletrônicos. Disponível na Internet. http:/www.elogica.com/br/users/ gmoura/refer.htm 9 dez. 1996.

Percebe-se que o modelo anterior é mais simplificado, pois não designa o suporte [on-line], bem como não menciona o local e data em que o documento foi "publicado" e não utiliza o símbolo de par ordenado, $<>$, no endereço eletrônico.

Utiliza-se também a apresentação material da ABNT para referências bibliográficas, tais como o sobrenome do autor em caixa alta e voltar a referência debaixo da terceira letra do sobrenome do autor. A última data, sem colchetes, refere-se à consulta ao site.

O Modelo de número 3 (Moura, 1996), possui os seguintes itens:

\section{MODELO 3: Moura (1996)}

MOURA, Gevilacio Aguiar Côelho de. Citações e referências a documentos eletrônicos. [online] Disponível na Internet via WWW.URL:http:// www.elogica.com./br/users/gmoura/refere.htm. Arquivo capturado em 15 de maio de 1996.

Com relação aos demais modelos arrolados, o de número 3 não apresenta alterações em sua forma, sendo, na verdade, uma mistura dos dois modelos analisados anteriormente, onde não se volta a segunda linha da referência debaixo da terceira letra do sobrenome do autor, onde não se destaca o título, mas aparece o tipo do suporte e a recomendação da ISO para a via WWW, em português.

Uma informação que parece oportuna no Modelo 3 seria mencionar "Arquivo capturado" ou "Arquivo consultado em", antes da data de acesso.
Após a apresentação dos modelos, algumas questões deverão ser problematizadas com relação às referências.

A primeira questão seria a referenciação de uma informação contida em um site, entretanto capturada na forma impressa e como tal possuindo a paginação onde determinada informação aparece, como no caso dos textos de Moura (1996) e Kraemer et al. (1996), que apesar de ser hipertexto, tem possibilidade de impressão e utilização do meio impresso, com paginação, inclusive. Na hora de citar e referenciar, deve-se misturar o imaterial com o material em seu loco citatum, ou seja, no lugar físico material de citação, deve-se incluir a paginação?

É o que está sendo sugerido no modelo de referência de artigos on-line, por exemplo, que possuem o equivalente impresso, mas estão também disponíveis em web-pages com endereços eletrônicos. Para tal situação, analisou-se a sugestão da ISO, de acordo com Ferreira \& Kroeff (1996), conforme o modelo abaixo:

\section{MODELO 4: ISO apud Ferreira \& Kroeff (1996)}

LUCAS, Clarinda Rodrigues. Os senhores da memória e do esquecimento. Transinformação [on-line]. 1998, vol. 10, no 1 [cited 1998-10-17], pp. 1-6. Available from World Wide Web <URL:http://www.pucamp.br/ $\sim$ biblio/transinformaçao/pag 87.html>

onde:

A referência segue a seqüência do artigo impresso até o título do periódico.

[on-line]: para o tipo de suporte, ou seja:

[on-line] quando localizado na rede Internet;

[disquetes] e [CD-Rom] quando possui o suporte material.

data:

a primeira data refere-se ao ano do volume;

a segunda seria citação do artigo na rede, entre colchetes, sendo que, antes dessa, a ISO recomenda a data de atualização/revisão, sem colchetes (não constante no exemplo), o que não faz sentido, pois o artigo, depois de “publicado”, não pode ser atualizado (a não ser que se esteja apontando para a atualização do site). 
Available from World Wide Web, ou seja, disponível na WWW, e a ISO, de acordo com Ferreira \& Kroeff (1996, p. 8-9), recomenda:

documentos eletrônicos on-line via www devem inserir a expressão supracitada seguida da URL (endereço eletrônico) entre "brackets" $<>$, por exemplo: Available from Word Wide Web:<URL:http://www.elogica.com.br/ users/gmoura/refere.htm $>$;

$>$ documentos eletrônicos on-line disponíveis nos serviços da Internet, exceto o WWW, devem inserir a expressão "Available from Internet".

\section{CONCLUSÃO}

A forma textual das web-pages, como já apontado, não possui a formalidade dos tradicionais textos de conhecimento, que são impregnados de itens do paratexto, embora as formas textuais já consagradas com os artigos científicos, por exemplo, estejam se valendo da linguagem html (característica do hipertexto) na rede Internet para sua veiculação.

Essa estrutura textual menos formalizada, cujos elementos do paratexto não se fazem necessários, vai se refletir, possivelmente, na simplificação da representação da informação da documentação eletrônica, se pensarmos que a representação da informação é o reflexo da linguagem e de uma certa organização textual (representação do conhecimento).

Tal reflexo se dará especialmente na representação temática, possibilitando um modelo mais simples, sem as relações hierárquicas que o modelo das classificações tomou emprestado das ciências e dos textos impressos. Assim, a classificação cede lugar aos tesaurus ou vocábulos livres na consulta ou organização dessas informações na rede. Estamos deixando para trás o modelo da hierarquia, da tradicional árvore do conhecimento, da sumarização do seccionamento numérico dos textos.

Mesmo admitindo que o hipertexto traz características da forma impressa (porque nossa cultura verbalista não iria deixar de fazê-lo), essa nova forma, que põe a palavra em movimento, parece desestruturar a lógica linear estabelecida na cultura do impresso. Assim, a rede semântica de significações dos sites, por intermédio dos links, parece estar livre da classificação fixa das bibliotecas e da materialidade do objeto livro.
O hipertexto, por sua vez, é uma nova forma textual (mesmo que incorporado em formas textuais impressas já conhecidas) e tem modificado a leitura dos documentos em rede, dada a interação das unidades lógicas em um só espaço semântico/digital dentro das web-pages. Tais espaços estão sendo organizados espontaneamente, ou seja, a organização e a lógica das mesmas já são demonstradas aos leitores, por meio do mapa do site e do mapa de links, proporcionando, assim, uma apreensão do todo, da macroestrutura do site e as suas ligações.

As home pages, por meio dos sites, têm demonstrado uma tendência absoluta na rede, em termos de documentos, pois elas abrigam desde espaços destinados à informação publicitária (talvez a maioria) até informações factuais, dados, como também os full-texts, no caso de monografias e periódicos.

Apesar desta grande miscelânea que tem demonstrado ser a Internet, ou seja, apresentar-se como uma grande vitrine de informações e não de conhecimento, de transporte físico de documentos, ou ainda de ferramenta por outros, não podemos ignorar a mudança cognitiva que este novo meio de comunicação, mediante suas formas textuais, está trazendo à sociedade, e por isso mesmo não podemos descartá-la como objeto de pesquisa. Devemos lembrar, sempre, que os leitores não se confrontam somente com textos abstratos ideais e os bibliotecários só com documentos materiais, mas ambos confrontam-se com textos instituídos de formas textuais, que produzem sentidos na leitura e, por conseguinte, na cognição e nas representações.

Estudar a Internet implica, também, um olhar sobre a comunicação, os saberes e competências do mundo contemporâneo, pois, tudo que se dava em separado, na sociedade da "ordem bibliográfica", com seu suporte (ou canal) consolidado, está tudo junto no mesmo espaço semântico/digital.

Assim, a home page de uma editora (que antes era um catálogo impresso), leva, através de um link, à outra de uma universidade (que antes poderia ser um catálogo da instituição) que, por sua vez, tem um link com a revista, que leva à impressão de um artigo científico (que antes só se fazia mediante a posse do objeto impresso). Em resumo, uma justaposição de discursos e meios de comunicação de massa no ciberespaço, que Lévy (já citado) aponta como um "imenso plano semiótico desterritorializado". 
Outra questão que merece estudos profundos é o conceito de "obsolescência", não só com relação ao eletrônico, mas também aos impressos em decorrência da coexistência com os eletrônicos.

É uma questão que nos remete ao conceito de arquivo ou memória do conhecimento para a humanidade, cujo processo se dá por meio da análise documentária (dos documentos impressos), que, visando a transformar o conhecimento em informação, propicia ao mesmo o status de referência. Em decorrência disso, o conhecimento teria maior alcance e melhor difusão, no tempo e no espaço.

Entretanto, os espaços digitais, menos estáveis, desatualizam-se a cada lançamento de novos produtos no mercado, novos ambientes de trabalho, novas capacidades tecnológicas. Assim, o conceito de obsolescência torna-se muito imediato, se comparado aos textos impressos, pois as infovias podem alterar suas rotas e mesmo os sites vão se alterando e sofrendo atualizações ou mesmo saindo da rede. De que maneira poderão estes registros ficar para a humanidade? Não ficarão porque são considerados comunicação informal? E os documentos eletrônicos de conteúdo com suporte digital não serão também voláteis?

Com relação à descrição física dos documentos eletrônicos, percebe-se que a ISO, pelas recomendações, está descrevendo as formas textuais de conteúdo, sobretudo, de monografias e periódicos (e não das webpages) e, ao fazê-lo, está aproximando em muito a descrição (que deveria ser em nível de referência) da representação descritiva.

Assim, cabe ao organismo nacional de normalização, no caso a ABNT, estudar os modelos da ISO de tal modo a recomendá-los da forma mais inteligível possível para que um número maior de pessoas possam utilizá-los. Talvez a saída, nesse caso, seja uma simplificação do modelo e uma aproximação aos modelos já conhecidos e incorporados na sociedade, resguardando as especificidades do documento eletrônico.

Por fim, lembrar que discutir os conceitos científicos é necessário não só à compreensão dos modelos existentes, mas também indispensáveis à atualização de conceitos técnicos da área.

\section{REFERÊNCIAS BIBLIOGRÁFICAS}

1. AMERICAN PSYCHOLOGICAL ASSOCIATION. Publication of American Psychological Association. 5. ed. Washington, 1995.

2. ARAÚJO, Emanuel. A construção do livro: princípios de editoração. Rio de Janeiro: Nova Fronteira, 1995.

3. CHARlAB, Sérgio. Oráculos. Editoras online. Disponível na Internet. http://www.editoras.com/oraculos/index.html 11 out. 1998.

4. CHARTIER, Roger. O mundo como representação. Estudos avançados, v. 11, n. 5, p. 173-191, 1991.

5. A ordem dos livros: leitores, autores e bibliotecas na Europa entre os séculos XIV e XVIII. Brasília : Ed. UnB, 1994.

6. DIJK, Teun A. van. Cognição, discurso e interação. São Paulo : Contexto, 1992.

7. EDITORAS online. Disponível na Internet. http://www.editora.com 11 out. 1998.

8. FERREIRA, Sueli Mara S.P., KROEFF, Márcia S. Referências bibliográficas de documentos eletrônicos. São Paulo : Associação Paulista de Bibliotecários, 1996. (Ensaios APB, v. 1-2, n. 35-36)

9. HOGDSON apud AMORIM, Maria Thereza. Documentação de trabalhos. Educar, v. 1, n. 1, p. 55-73, set./dez. 1981.

10. KRAEMER, Lígia Leindorf Bartz; LOURENÇO, Luiza de Fátima Pilati Mendes; RESMER, Maria José; MARCHIORI, Patricia Zeni. Referência bibliográfica de informações e documentos eletrônicas: uma contribuição para a prática. Curitiba : InfoMatrix, 1996. 1 disquete, $31 / 2$ pol.

11. LANCASTER, F.W. The evolution of eletronic publishing. Library Trends, v. 43, n. 4, p. 518-25, Spring 1995.

12. LE COADIC, Yves-François. A ciência da informação. Brasília : Briquet de Lemos/Livros, 1996.

13. LÉVY, Pierre. A inteligência coletiva: por uma Antropologia do ciberespaço. São Paulo : Loyola, 1998.

14. As tecnologias da inteligência: o futuro do pensamento na era da informática. Rio de Janeiro : Ed. 34, 1996.

15. MACEDO, Alberto Levy. Ferramentas de busca. Guia da Internet.br: a revista brasileira da Internet, v. 1, n. 2, p. 16-19, [1996].

16. MARTINS, Salete Maria; LEME, Maria A. de Toledo; SOUZA, Márcia Izabel Fugisawa. Normas de referenciação e descrição bibliográfica para o sistema EMBRAPA de informação: versão preliminar. Campinas : EMPRABA, 1996.

17. McKENZIE, Donald F. Bibliography and the Sociology of texts. London : The British Library, 1986.

18. MONTEIRO, Silvana Drumond. Norma e forma: a normalização do livro brasileiro. Campinas, 1996. Dissertação (Mestrado em Biblioteconomia) - Departamento de Pós-graduação em Biblioteconomia, Pontifícia Universidade Católica de Campinas.

19. MOURA, Gevilacio Aguiar Côelho de. Citações e referências a documentos eletrônicos. Disponível na Internet. http:// www.elogica.com/br/users/gmoura/refer.htm 9 dez.1996.

20. SANTAELlA, Lúcia. Por uma classificação dos signos visuais. Face, São Paulo, v. 2, n. 1, 1989.

21. SANTAELLA, Lúcia; NÖETH, Winfried. Imagem, cognição, Semiótica, mídia. São Paulo : Iluminuras, 1998. 